\title{
Gesto e gestus: contribuições para teoria e prática do gesto em cena
}

\section{Resumo}

Carlos Alberto Silva ${ }^{1}$

A pesquisa propõe pautar gesto como operador cênico tendo como contraposição movimento e ação. Para alargar os referenciais teóricos de praxe nas artes cênicas, busca interlocução com outras áreas, em particular com os estudos da gestualidade. O intuito é verificar se a proposição pode ser um diferencial em processos formativos e criativos. O caminho para tanto implica exame bibliográfico sobre poéticas teatrais estabelecidas, estudo de caso, epistemologia dos saberes profissionais e performance.

Palavras-chave: cinésica, cena, corporeidade, expressão, intérprete

\begin{abstract}
The research proposes guided scenic gesture as an operator having movement and action as opposition. To broaden the theoretical usual referrals, seeking dialogue with other areas, in particular the study of gestures. The purpose is to verify that the proposition can be a differentiator in the formative and creative processes. The way for that implies examination of the literature on poetic theatrical set, case study, epistemology of professional knowledge and performance.
\end{abstract}

Keywords: embodiment, expression, performer, kinesic, scene

\section{Resumen}

La investigación propone gesto escénico guiada como un operador que tiene como movimiento y acción en contra. Para ampliar las referencias teóricas usuales, buscando el diálogo con otros sectores, en particular el estudio de los gestos. El objetivo es verificar que la propuesta puede ser un diferenciador en los procesos formativos y creativos. El camino implica tanto el examen de la literatura sobre el conjunto de teatro poético, estudio de casos, la epistemología del conocimiento y de desempeño profesional.

Palabras clave: corporeidad, escena, expresión, intérprete, kinesicos

\section{As artes precisam começar a prestar atenção ao Gestus. ${ }^{2}$}

O intuito deste artigo é trazer a reflexão sobre o gesto entendido como operador cênico de uma maneira geral e, especialmente, em torno da concepção de Brecht, resultados de pesquisas e formulações de campos de conhecimento que revelam

\footnotetext{
1 Doutorando pelo PPGAC USP na área de Pedagogia do Teatro (Formação do Artista Teatral) sob a orientação de José Batista Dal Farra Martins (Zebba Dal Farra). Bolsa de fomento: CAPES.

2 BRECHT, Bertld. Música - "Gestus", (p. 84) in ÜBER GESTISCHE MUSIK, 1932. Tradução de Luiz Carlos Maciel. Ensaio publicado na $1^{\text {a }}$ edição dos Schriften zum Theater, 1957
} 
potenciais contribuições para seu dimensionamento na constituição da cena e na compreensão e emprego no trabalho de atuação.

Um dos enquadramentos delimita o gesto como articulador expressivo e coparticipante da linguagem cotidiana. Contudo, entre aqueles que se dedicam aos estudos da gestualidade, como Kendon ${ }^{3}$, boa parte dos escritos sobre este tema resultaram em catalogações, classificações e instruções de uso na oratória e no teatro. A constância em considerá-lo posiciona sua importância na construção expressiva, em particular na linguagem teatral. Daí sua designação como um operador cênico e não como um mecanismo eventual e fortuito de algum entendimento estético.

Os possíveis subsídios indicados para a reflexão são oriundos de enfoques que tomaram vulto na primeira metade do séc. XX, firmando-se como presença significativa e vinculam-se a processos provenientes de ciências que começam a se estabelecer no final do século XIX. Essa abordagem é, assim, relativamente recente e ainda bastante sujeita a controvérsias, o que parece muito profícuo, tanto quanto métodos tecnológicos disponíveis neste campo de conhecimento.

Tentar trilhar um caminho que proponha colocar em diálogo compreensões advindas de áreas normalmente tidas como conflitantes, como ciência e arte é, frequentemente, visto como terreno inóspito de transitar. No entanto, pelo menos a partir do século XX, registra-se como postura recomendada por vários artistas e teóricos.

Localizar, antes de tudo, o que está sendo referido no emprego de determinada palavra mostra-se consequente para quaisquer que sejam os limites de investigação, ainda mais quando tal palavra é transformada em conceito e tem um uso peculiar.

O que impulsionou a reflexão aqui sugerida teve origem na minha percepção da diversidade de atribuições de significados e sentidos dados à palavra gesto em diversos contextos, dinâmica que, normalmente, resulta da fricção do uso corriqueiro da linguagem.

Sem nos eximirmos de ambientes exclusivos podemos notar que há tantos engates e encaixes do termo em foco, que torna seu uso um recurso para atestar certa ordem de significação. Se não se sabe ao certo o que alguma coisa ou fenômeno pode vir a ser, recorre-se a este vocábulo.

Ouvimos, aprendemos e usamos a expressão em pauta muito antes de com ela convivermos no campo cognitivo, semântico, expressivo e estrutural das artes cênicas.

3 KENDON, A. Gesture: Visible Action as Utterance. Cambridge: Cambridge University Press. 2004 
Seria precário tentarmos nos desvencilhar do caráter ao mesmo tempo perecível e cristalizador das palavras: esta relação está em nós!

Contudo, indago se esse procedimento contribui para a construção de uma linguagem estética como a que está em foco. Talvez a resposta afirmativa a essa pergunta traga contribuições fundamentais e seja tão necessária quanto a via que desejo explorar.

Optamos por uma postura menos conformada a certos padrões no trato com conceitos fundamentais, ao menos para esta área.

Ao ler, por exemplo, a tradução brasileira dos Schriften zum Theater ${ }^{4}$, dois eventos chamam a atenção do leitor seletivo: os termos gesto e Gestus são empregados com uma frequência muito maior do que outros operadores considerados fundamentais nas artes da cena; e a imensa maioria das vezes em que ocorre, o termo é posto entre aspas. Uma possível explicação vai ao encontro dos motivos que impulsionam a reflexão aqui sugerida, isto é, explorar diferenciações contextualizadas do emprego do termo.

Nos resta, pois, especular sobre os entendimentos para intuirmos como se relacionam na prática. Como não foram poucos os que se preocuparam com este tema, mostra-se procedente aludir, mesmo que parcialmente, diferentes definições e delimitações de gesto.

Consta entre muitos significados postos em termos lexicais, que de certa forma refletem o uso ordinário e sedimentado das palavras, gesticulação, movimento do corpo, especialmente das mãos, braços e cabeça - voluntário ou involuntário - que revela estado psicológico ou intenção de exprimir ou realizar algo; aceno, mímica; expressão singular; aparência, aspecto, fisionomia; maneira de se manifestar; atitude; ação. Há, eventualmente, o acréscimo dos olhos e delimita declamação, além de conversação, como situações onde este evento acontece. Por fim, a consulta à raiz gest-, denota andar com, ter consigo, trazer em cima do corpo; produzir, criar; ser levado em liteira; estar grávida (donde gestatio,ónis).

Não obstante a irradiação de sentidos devido à circulação por fontes emissoras, momentaneamente soberanas na atribuição de significado, uma expressão como esta estaria fadada mesmo a ter muitos desdobramentos. Os significados mencionados perfazem apenas uma parte não muito considerável dos constados. Não bastasse a

4 BRECHT, Bertold. Estudos Sobre Teatro. Tradução Fiama Pais Brandão. Rio de Janeiro: Ed. Nova Fronteira, 1978. 
multiplicidade de sentidos, há quatro que particularmente merecem destaque para demonstrar fluidez de significados: andar com, ter consigo, trazer em cima do corpo e estar grávida(o). Neste viés, pouca coisa estaria excluída do rol dos gestos.

Não é, portanto, sem razão a necessidade de circunscrever que fenômenos assumir sob esta palavra. De uma maneira geral, parece que nada se desvia muito dos entendimentos acima discriminados. Porém, mesmo um rápido levantamento das formulações do termo gesto como um constructo evidencia o esforço de delimitar o que possa viabilizar e organizar a observação, coleta, catalogações, classificações, enfoques de abordagens, paradigmas e outros recursos com vistas a reunir e adaptar eventos para empreender reflexões que fundamentem a construção de compêndios em alguns casos, de métodos em outros e de estudos com caráter científico.

Até o momento, não sei se é consensual que os autores mais significativos até meados do século XX trataram o gesto prioritariamente como operador da oratória e/ ou das artes cênicas, exceto Rousseau ${ }^{5}$, mas o que se constata é que boa parte das publicações se encaminha nestas duas direções.

Conforme Kendon ${ }^{6}$, os gestos têm sido classificados de acordo com critérios bastante diversificados, o que demonstra, também, as características selecionadas para identificar o que estava sendo assumido. Um cuidado constante e elementar é distinguir a topologia corporal envolvida na ação expressiva; se os movimentos são voluntários; naturais ou convencionais; se os significados são estabelecidos por índice, ícone, símbolo; se são literais ou metafóricos; o modo de vínculo com a fala; qual o domínio semântico, isto é, se são objetivos ou subjetivos.

Kendon reporta, principalmente entre os que tinham como alvo a oratória, critérios de classificação relacionados ao conteúdo propositivo do discurso: se pontuam, organizam, estruturam ou indicam o tipo de discurso, se desempenham papel secundário ou prioritário na interação comunicacional, se funcionam como reguladores discursivos; entre outros.

Apesar de não se ter logrado um esquema inequívoco, unificado e definitivo de categorização e dos aspectos ou dimensões enfatizados dependerem de objetivos particulares colocados sob questão, é de ampla aceitação ser o dado gestual um recurso expressivo e seu uso abrange uma larga finalidade de propósitos. Assim, é

5 ROUSSEAU, Jean-Jacques: Ensaio sobre a Origem das Línguas. Trad. Lourdes Santos Machado. Coleção os Pensadores. Ed. Abril Cultural. 1983.

6 KENDON, A. Gesture: Visible Action as Utterance. (pp. 84 -107) Cambridge: Cambridge University Press. 2004 
oportuno conhecer algumas sistematizações mesmo encarando-as apenas como instrumentos provisórios.

Kendon (2004) destaca Johan Jakob Engel (1741-1802) que reserva o termo gesto para ações expressivas como signos externos de paixões internas e atividade mental e apoia uma distinção entre movimentos originados de mecanismos biomecânicos puros daqueles que dependem da atividade da alma provocados pelos pensamentos e sensações; são ainda divididos em três tipos: ações figurativas, expressivas e fisiológicas. Tal classificação, portanto, propõe não englobar todos os tipos de movimentos corporais como compondo o sistema daqueles que são identificados como gestos. Assim, são discriminados movimentos, cujo montante, consequentemente, é muito maior do que daqueles que são entendidos e aplicados como gestos.

Note-se que é comum a recorrência às expressões ação e movimento na definição de gesto. Por vezes confundem-se como sinônimos, sendo que, na moderna terminologia, alguns preferem circunscrever gestos aos "movimentos intencionais", embora admita-se que há movimentos intencionais que não são entendidos como gestos. Restaria delimitar, neste contexto, que significado de 'intencional' está em jogo.

Na mesma trilha, Gilbert Austin (1753-1837) classificou gestos para e em atores e oradores. Tratou extensivamente da função da movimentação das mãos na estruturação e pontuação do discurso verbal. Sua tipologia classifica gestos em não significativos e significativos e estes são subdivididos em naturais (expressam sentimentos, paixões e desejos) e instituídos, que não acompanham a fala.

Há, enfim, os que no decorrer do século $X X$ focalizam o gesto fora do contexto do púlpito e do palco.

David Efron, outro autor selecionado por Kendon, realiza em 1941 a primeira tentativa no séc. XX de tratar da relação entre gesto e fala e busca sintetizar modos de observação e de maneiras de uso.

Foca mais os gestos manifestados pelos movimentos das mãos e dos braços, tratando-os sob três perspectivas de relação: espaço-temporal, inter-locucional e linguística - dividida em lógica ou discursiva e objetiva. Esta última categoria abrange gestos que operam independentemente da fala e se subdividem em dêiticos e os fisiográficos, os quais são, ainda, separados em iconográficos e cinetográficos (kinetographics), ambos muito próximos dos gestos espaço-temporais. Por fim, há ainda, os simbólicos ou emblemáticos. 
Tal como Efron, Wilhelm Wundt (1973) não tratou do gesto no contexto teatral, apesar da influência de Engel. A classificação de Wundt é principalmente semiótica e segue uma divisão orientada pela maneira como a ação gestual se relaciona com o significado do gesto. Sugere uma categoria de gestos demonstrativos e descritivos divididos em mímicos, conotativos e simbólicos. Não se centra na relação com a fala, mas ocupa-se inteiramente da operacionalidade dos gestos em sua própria forma de existência - que chama de linguagem dos gestos. Nisto difere de todos os outros autores. Paul Ekman e Wallace Friesen também se dedicaram mais à 'comunicação e comportamento não-verbal', redimensionando os estudos de Efron. Entendem 'comportamento não-verbal' no julgamento de atitudes, personalidades e estados emocionais, tendo como base atitudes e movimentos corporais e faciais de pessoas observadas. São propostos três parâmetros fundamentais para que se entenda qualquer instância de 'comportamento não-verbal': origem - se é aprendido ou inato -, uso e codificação. Há, ainda, outras subdivisões.

Na avaliação de Kendon o que torna difícil a aplicação de uma extensa tipologia é que uma mesma ação pertence a diferentes categorias dependendo do ponto de vista tomado para análise.

David MacNeill retoma o entendimento do gesto e da fala como participantes na construção da expressão e vistos como componentes inseparáveis, num processo dialético. MacNeill desenvolveu um sistema de categorias que tem sido amplamente adotado. Seu interesse circunscreve-se à gesticulação espontânea que acompanha "involuntariamente" a fala, e é melhor localizado tomando como referência o Kendon's Continuum, uma escala elaborada que adota como parâmetro uma série de dimensões em termos de quais gestos podem ser comparados entre si e como isso pode ser feito. Num dos polos, ficam os gestos que funcionam independente da fala e são altamente convencionalizados, composicionais e lexicais em sua organização e estrutura. No outro polo está a gesticulação: movimentos idiossincráticos espontâneos das mãos e braços que acompanham a fala. No meio localizam-se os 'emblemas', gestos que funcionam como expressão completa em si, e 'pantomimas' ou 'mime', que podem ser empregados em alternância com a fala, servindo como equivalente funcional de palavras ou frases.

A questão teórica se refere às diferentes propriedades que o gesto assume conforme a demanda comunicativa. Este seria um caminho para classificação e análise das diversas situações expressivas, como procuram explorar os autores dos estudos 
da gestualidade. Com as devidas adequações e adaptações, penso que especular sobre essa possibilidade na análise da cena seria uma contribuição diferenciada.

O interesse e o esforço de MacNeill na classificação dos gestos referem-se e aplicam-se àqueles que, no continuum de Kendon, estão na gesticulação. A primeira distinção é entre gestos imagísticos, ações figurativas para Engel, e não-imagísticos, ou dêiticos para Efron; a estes MacNeill junta os beats: movimentos que marcam um segmento do discurso ou uma estrutura rítmica da fala.

Há, ainda, a proposta de escala de Marianne Gullberg definida pelo grau de iconicidade do gesto: vai dos beats, os menos icônicos, até os inteiramente icônicos. Quanto maior o grau de iconicidade de um signo, tanto menor o seu grau de abstração ou esquematização.

Para o presente propósito, os exemplos de classificação esboçados são suficientes. Importante é destacar que, no geral, mãos e braços são reconhecidos como componentes de um sistema expressivo em separado do restante do corpo; os esquemas apresentados devem ser considerados pelo fim ou abrangência de ações gestuais às quais se referem; se, e como, conectam-se à fala e como são ponderados os tipos de distinções e categorizações semióticas.

Por outro lado, há o foco nas várias formas expressivas usadas pelos atores, operadas como sucessão de atitudes na construção cênica do drama, além das propriedades linguísticas do gesto como um meio autônomo, sem interesse especial na relação entre ações corporais e discurso. Mesmo assim, verifica-se controvérsias entre os diferentes esquemas na consideração sobre os vínculos entre discurso e expressão corporal, se esta não difere substancialmente de gesto, o que é da maior relevância para esta discussão.

Em resumo, parece ser amplamente reconhecível que gestos são expedientes expressivos usados para apontar e representar por meio de soluções corporais algo que é relevante para o conteúdo referencial do que se deseja comunicar e muitos assumem a importância da função gestual para o recorte da estrutura lógica do discurso. Entendem o gesto sob a perspectiva de uma atividade significativa para compreender a expressão do falante e consideram que desempenha um papel importante para esta articulação. Todos concordam que isto acontece num contexto socialmente significativo.

Do exposto até aqui, decorrem algumas questões estreitamente vinculadas à nossa inquietação, para a qual Brecht tem uma importância definitiva. No meu enten- 
dimento, para ele, o gesto se torna mais que um componente da linguagem teatral e estende-se, em seu significado e operacionalidade ao Gestus, concebido como um divisor nas artes e como um princípio estético que, segundo a visão brechtiana, deveria substituir o princípio da imitação, ou da mimese. ${ }^{7}$ Afirma que uma mudança desta ordem "marcaria uma profunda revolução na arte dramática, uma vez que na dramática aristotélica, fundamentada no princípio da mimese, o herói é colocado, pelas ações, em situações que lhe põem a descoberto o seu ser mais íntimo". No Gestus em contrapartida o que está em relevo é um caráter eminentemente social e político. Não é, portanto, casual o subtítulo posto no original dos "Estudos sobre teatro" que não aparece na tradução brasileira tomada como base para este artigo. $^{9}$

Numa primeira impressão, a noção que fundamenta o Gestus e a dos autores citados parecem convergir para a conclusão de ser o gesto um evento imerso e dependente da experiência em um todo socialmente significativo. ${ }^{10}$ Sob certos aspectos, existe, de fato, uma sintonia. Contudo, ponderar certas dimensões pode trazer nuances e problematizar mais ampla e consequentemente a reflexão.

Diante da ênfase dada por Brecht à necessidade da arte cultivar o gesto que tenha significado social e não aquele com função apenas ilustrativa e expressiva, conclui-se que o dramaturgo alemão distingue gestos aos quais faltam tal significado. ${ }^{11}$ Este ponto de vista contrasta com a noção do fenômeno gestual não acontecer sem um significado social relevante e nem fora de um contexto socialmente significativo.

Desta forma, parece ser importante descobrir ao que diz respeito o conceito de 'social'.

No que concerne a Brecht, muitas evidências levam a pensar que diz respeito a um engajamento e posicionamento político. No exemplo dado por ele mesmo, a reação corporal defensiva frente à ameaça de um cão feroz pode ser um Gestus se, por meio dela, ficar evidente uma luta entre uma pessoa maltrapilha e um cão de guarda de uma

7 BRECHT, Bertold. Música - "Gestus", (p. 84) in ÜBER GESTISCHE MUSIK, 1932. Tradução de Luiz Carlos Maciel. Ensaio publicado na $1^{a}$ edição dos Schriften zum Theater, 1957

8 BRECHT, Bertold. Estudos Sobre Teatro. Tradução Fiama Pais Brandão. Rio de Janeiro: Ed. Nova Fronteira, 1978.p. 186.

9 O título original é: Schriften zum Theater - Über eine nicht-aristotelische Dramatik, na edição da Surhrkamp Verlag - Berlin und Frankfurt am Main, 1957. A tradução literal da expressão Schriften é 'ecritos'.

10 É preciso reforçar que, para Brecht, gesto e Gestus não são necessariamente a mesma coisa, e que o último tem um sentido muito mais desdobrado e metafórico do gesto.

11 BRECHT, Bertold. Estudos Sobre Teatro. Tradução Fiama Pais Brandão. Rio de Janeiro: Ed. Nova Fronteira, 1978. p. 39 
propriedade abastada. ${ }^{12}$ Mas não é qualquer reação corporal a investidas de animais que a torna um Gestus.

Meu foco de atenção é sobre o gesto, assim, meu interesse no Gestus é o que nele há daquele. Para Brecht o Gestus não se restringe a aspectos apenas corporais, assim, sua menção fica nos limites de buscar uma compreensão conceitual. Na música, Gestus, diz ele, é "importante, no entanto, que este princípio, que atenta ao Gestus, possibilite ao compositor tomar sua postura política na composição musical. Para isso é necessário que ele de forma a um Gestus social." ${ }^{13}$ Exemplifica com uma suposta cantata sobre a morte de Lenin. Sobre a tendência emocional que deveria conter tal obra afirma que "uma certa atmosfera festiva diria pouco, já que frente à morte de um inimigo pode valer como conveniente. Irá contra a "fúria cega da natureza", que arranca os melhores da comunidade em tempos desfavoráveis, não seria um Gestus comunista, ..."14 Enfim, citações desta espécie demonstram, ao menos tendencialmente, qual a compreensão sugerida sob "socialmente significativo" ou "significado social".

No geral, os enunciados das outras áreas mencionadas orbitam em torno de entendimentos sociológicos e antropológicos, o que não significa isenção ideológica, contudo, há dados de caráter estrutural que ampliam o exame do tema.

Vamos, então, esboçar algumas argumentações. Brecht ressalta a importância especial que o "gesto social" dos atores adquire do prisma estético:

\footnotetext{
A dicção e o 'gesto' precisam ser cuidadosamente selecionados, e, além disso, devem ter amplitude. Visto que o interesse do espectador é canalizado exclusivamente para o comportamento das personagens, o Gestus destas deve ser, falando em termos puramente estéticos, significativo e típico. ${ }^{15}$
}

Independentemente da adjetivação que se queira atribuir ao gesto, há indícios fortes que o Gestus é construído como operador cênico e como concepção estética por ser elemento de composição que conflui para uma estabilização, mesmo que não definitiva. Aqui falamos restritamente do intérprete.

12 Idem (pp. 193 a 194)

13 BRECHT, Bertold. Schriften zum Theater: Über eine nicht aristotelische Dramatik. (p.252) Surkamp Verlag, Berlin und Frankfurt am Main. 1957.

Wichtig hingegen ist, daß dieses Prinzip des auf den Gestus Achtens ihm ermöglichen kann, musizierend seine politische Haltung einzunehmen. Dazu ist nötig, daß er einen gesellchaftlichen Gestus gestaltet. (tradução minha)

14 Idem (p. 254) Ein gewisses feierliches Auftreten besagt noch wenig, da dies auch gegenüber dem Feind im Falle des Todes für schicklich gelten kann. Zorn über die 'blind wütende Natur', die den besten der Gemeinschaft zur ungünstige Zeit entreißt, wäre kein kommunistischer Gestus, ... (tradução minha)

15 BRECHT, Bertold. Estudos Sobre Teatro. Tradução Fiama Pais Brandão. Rio de Janeiro: Ed. Nova Fronteira, 1978.p. 39. 
O mecanismo de estabilização, como deduzimos, apoia-se nas conclusões de Tatit em seus estudos sobre a arte do cancionista ${ }^{16}$ e sugerimos que tem funcionalidade análoga para a análise do gesto em cena.

A canção como linguagem artística implica o ajuste de dois campos semióticos o linguístico e o musical - equilibrados pelo cancionista que privilegia a entoação para estender a fala ao canto. A originalidade está em criar uma obra perene com os mesmos recursos utilizados na produção efêmera da fala cotidiana pura, cuja função é dar formas instantâneas, com invólucros fônicos descartáveis, a conteúdos abstratos que é o que deve ser apreendido. Por isso, a melodia da fala não é estável, não se repete, não mantém ritmo periódico, não se estabiliza nas frequências entoativas e não adquire autonomia.

O cancionista recorre às tensões melódicas camufladas na fala, que lhe possibilita estabilizar as frequências dentro de um percurso, criando zonas de tensão que estabilizam um sentido próprio para a melodia. Para tanto, precisa de uma percepção, mesmo que, e sobretudo, intuitiva de que a voz que fala interessa-se pelo que é dito e a voz que canta, pela maneira de dizer.

Da fala ao canto há um processo geral de corporificação: da forma fonológica à substância fonética e desta ao som cantado. É a estabilização da frequência e da duração por leis musicais que passam a interagir com as leis linguísticas. Contudo, o projeto entoativo sustenta o efeito de naturalidade no mesmo campo sonoro em que se dão as estabilizações programadas pelo compositor.

A hipótese é que o mesmo acontece com a gesticulação e o gesto como operador cênico - o primeiro elemento é cristalizado no segundo na composição teatral e, do que se pode apreender das ponderações e registros de seus trabalhos, Brecht cultiva essa via radicalmente. Nos limites deste artigo não cabe estender muito mais estas proposições pois demandaria uma investigação mais apurada, porém, a sugestão é que o caminho de exame teria como ponto de partida a noção da gesticulação estar para o Gestus na corporeidade como a voz falada está para a voz cantada. Gesticulação e fala são recursos expressivos envoltos por um invólucro instável e descartável. Já o Gestus corporal, à maneira da canção, seria o expediente estabilizado no performer. Assim, analogamente à voz que fala na voz que canta, a extensão da mera gesticulação no Gestus.

16 TATIT, Luis - O Cancionista. São Paulo: Editora da Universidade de São Paulo, 1996. (p. 9 -27) 
Do ponto de vista das pesquisas e formulações teóricas apontadas aqui, esta interpretação do enfoque de Brecht estaria em torno do polo de gestos altamente convencionalizados, composicionais e lexicais, supondo que este seja o passo seguinte em um processo de seleção cuidadosa, ou podemos usar a ideia de 'estabilização'. Outra gradação seria a proposta por Gullberg, pautada no grau de iconicidade do gesto, aqui a proposição brechtiana aproxima-se da categoria 'inteiramente icônico', supondo que essa qualidade seja indispensável para que os gestos ganhem contornos de Gestus e tenham amplitude, tornando-se significativos e típicos.

Estas escalas são feitas tendo como base tipos, e como tal não são encontrados frequentemente no mundo concreto. Contudo, como formulações de extremos, oferecem vetores para condução de análises.

Neste sentido, os beats e o polo dos 'movimentos idiossincráticos espontâneos das mãos e braços que acompanham a fala' não se enquadrariam por si só nos propósitos do Gestus que "não significa mera gesticulação. Não se trata de uma questão de movimentos das mãos, explicativos ou enfáticos para comentar ou sublinhar quaisquer passagens da peça, mas de atitudes globais."17 Uma linguagem é Gestus quando está baseada num "gesto", é adequada a determinadas posturas e mostra atitudes particulares adotadas pela pessoa que fala em relação às outras.

Para os estudos da gestualidade, resumidamente apresentados neste artigo, gesticulação não é um acontecimento sem complexidade e sem importância, se o termo 'mero' foi pensado com este significado, embora se reconheça que é trivial e corriqueiro, isto é, um recurso expressivo cotidiano. Pelo contrário, tem-se percebido cada vez mais o quanto é complicado e polêmico tratar de um assunto que envolve muitos eventos, vistos de variados modos e com finalidades específicas.

Outra coisa a ser ponderada é a relação dialética indicada na antítese contida no Gestus como 'atitude global' e 'a adequação a determinadas posturas que mostram atitudes particulares'. E, talvez o mais definidor, a relação de quem fala com os interlocutores que, em se tratando deste dramaturgo, não se restringem aos ocupantes da cena estrito senso.

Dada a diversidade e a subjetividade de sentidos estendidos, considero relevante destacar que todos os tratamentos aqui apontados concordam que o gesto é necessa-

17 BRECHT, Bertold. Schriften zum Theater: Über eine nicht aristotelische Dramatik. Berlin und Frankfurt am Main: Surkamp Verlag. 1957 
riamente perceptível. Daí Brecht expressar sua inquietação em como, no teatro, exibir gestos que são, a bem dizer, os usos e os costumes do corpo. E segue:

\begin{abstract}
Chamamos esfera dos gestos aquela a que pertencem as atitudes que as personagens assumem em relação umas às outras. A posição do corpo, a entoação e a expressão fisionômica são determinadas por um gesto social; as personagens injuriam-se mutuamente, cumprimentam-se, instruem-se mutuamente, etc. $\mathrm{O}$ ator apodera-se de sua personagem acompanhando com uma atitude crítica as múltiplas exteriorizações (grifo meu) que na maior parte das vezes é verdadeiramente complexa e contraditória, tornando impossível transmiti-la numa única palavra. ${ }^{18}$
\end{abstract}

A referência é "esfera dos gestos" e não Gestus.

A ênfase na dimensão sensível do gesto ganha importância dado o contraste com outras orientações técnicas e metodológicas de atuação. O que neste tipo de concepção parece claro é que o resultado final tem de ser perceptível; no caso deste operador cênico, em primeira instância, visível, porém, tomando os outros autores citados, arriscaríamos, exclusivamente visualizáveis. Neste sentido, é relativamente indiferente o que acontece no íntimo do ator se não evidenciar acontecimentos interiores aos sentidos dos espectadores. Pode, eventualmente, estar numa situação interior diferente de seu personagem, mas se sua construção e execução for dada à percepção sensível da plateia, terá cumprido seu propósito.

Ao discorrer sobre "distanciamento", é nítido o parecer de Brecht sobre o gesto como recurso à exteriorização de estados interiores.

Para extrair do verso um efeito de distanciamento pleno, será conveniente que o ator reproduza, primeiro, em prosa corrente, nos ensaios, o conteúdo dos versos, acompanhado, em certas circunstâncias, dos gestos para eles estabelecidos. (...) (...) todos os elementos de natureza emocional têm de ser exteriorizados, isto é, precisam ser desenvolvidos em gestos. O ator tem de descobrir uma expressão exterior evidente para as emoções de sua personagem, ou então uma ação que revele objetivamente os acontecimentos que se desenrolam no seu íntimo. (...) A particular elegância, força e graça do gesto provocam efeito de distanciamento. ${ }^{19}$

Esta forma de compreender o gesto vai ao encontro e é parte de muitas das formulações dos teóricos e analistas que servem de referência para este texto.

Diante dos argumentos apresentados, um gesto não assume a condição de social por ser caracteristicamente humano e, por outra via, não é humano condicionado à vida em sociedade. Apontamos algumas proposições que demonstram esta via de

18 BRECHT, Bertold. Estudos Sobre Teatro. Tradução Fiama Pais Brandão. Rio de Janeiro: Ed. Nova Fronteira, 1978. P.124-125

19 BRECHT, Bertold. Estudos Sobre Teatro. Tradução Fiama Pais Brandão. Rio de Janeiro: Ed. Nova Fronteira, 1978. p. 83 
sistematização como, por exemplo, a distinção entre gestos naturais e convencionais, admitindo-se que há uma gama dos que são ativados pelos seres humanos pela sua condição biológica e fisiológica.

Para que uma manifestação corporal não assumida tradicionalmente como gesto passe a ser assim entendida é necessário um esforço de contextualização dessa transformação, o que não acontece sem um significado social relevante ou fora de um contexto socialmente significativo, atribuindo ao gesto uma conformação de linguagem, ou de código.

Não obstante Brecht se referir ao gesto de dor como já sendo um gesto, portanto, do ponto de vista acima proposto, como elemento de contexto socialmente significativo, na continuidade de sua argumentação ele parece identificar tal gesto no rol dos movimentos humanos que não são necessariamente empregados como gestos, ao menos "não enquanto permanecer abstrato e tão geral que não se ergue acima da categoria puramente animal."20 Assim ele delimita como Gestus social, o gesto que, construído na linguagem cênica, permite conclusões sobre as circunstâncias político-sociais.

Identificamos um paralelismo com o que defendem os pesquisadores do gesto no que concerne a movimentos originados de mecanismos corporais de ordem fisiológica. Entretanto, seria ainda objeto de ponderação se a noção de 'erguer-se acima da categoria puramente animal' considera que o conteúdo de uma performance gestual tem validade se sua origem estiver vinculada a estados fisiológicos como a dor, por exemplo, lembrando que, na tipologia de Austin, esta dinâmica estaria entre os gestos significativos naturais que tornam aparente sentimentos, paixões e desejos, consequentemente, coerente com o contexto socialmente significativo.

O que não deixa dúvidas é o caráter sócio-político do Gestus, decididamente uma marca distinta, cujo paradigma é o gesto de trabalhar, porque toda atividade humana dirigida para o controle da natureza é uma tarefa social.

A concepção de Brecht ${ }^{21}$ de um teatro que tudo extrai do gesto implica a imprescindibilidade da coreografia concebida amplamente como movimentação cênica. A elegância de um movimento e a graça de determinada disposição coreográfica são, já

20 BRECHT, Bertold. Schriften zum Theater: Über eine nicht aristotelische Dramatik. Berlin und Frankfurt am Main: Surkamp Verlag. 1957.p. 78

21 BRECHT, Bertold. Estudos Sobre Teatro. Tradução Fiama Pais Brandão. Rio de Janeiro: Ed. Nova Fronteira, 1978. p.128-132 
em si, efeitos de distanciamento, e a invenção pantomímica é um precioso auxiliar da fábula.

O ator, como afirma Brecht, ao expor o gesto que informa a ação, apreende seu personagem descobrindo a "fábula", demarcada como composição global de todos os acontecimentos-gestos e apontada como sendo a tarefa fundamental do teatro. Cada acontecimento comporta um gesto essencial, mas só a partir do acontecimento global delimitado é possível chegar à personagem definitiva, que funde em si traços particulares. ${ }^{22}$

\section{Referências Bibliográficas}

AUSTIN, Gilbert. Chiromomia or Treatise on Rhetorical Delivery. London, 1806.

BRECHT, Bertold. Estudos Sobre Teatro. Tradução: Fiama Pais Brandão. Rio de Janeiro: Ed. Nova Fronteira, 1978.

. Música - Gestu, in ÜBER GESTISCHE MUSIK, 1932. Tradução de Luiz Carlos Maciel. Ensaio publicado na $1^{a}$ edição dos Schriften zum Theater, 1957

EFRON, David. Gesture and Environment. Gesture, Race and Culture, Etc. (Reissued.), Mouton, 1972.

EKMAN, Paul; FRIESEN, Wallace. The Repertoire of Nonverbal Behavior: Categories, Origins, Usage and Coding, Semiótica, V.1, N.1, p.49-98, 1969.

ENGEL, Johan Jakob. Ideen zur eine Mimik. Berlin: AugustMylius, 1785.

GULLBERG, Marianne. Gesture as a Communication Strategy in Second Language Discourse: A Study of Learners of French and Swedisch. Travaux de l'institut de linguistique de Lund, 35. Linguistic and Phonetics. Dissertation. 1998.

KENDON, A. Gesture: Visible Action as Utterance. Cambridge: Cambridge University Press, 2004

MCNEILL, David. What Gestures Reveal about Thought. Chigago: University of Chicago, 1992.

ROUSSEAU, Jean-Jacques. Ensaio sobre a Origem das Línguas. Trad. Lourdes Santos Machado. São Paulo: Ed. Abril Cultural, 1983.

22 BRECHT, Bertold. Estudos Sobre Teatro. Tradução Fiama Pais Brandão. Rio de Janeiro: Ed. Nova Fronteira, 1978. p.127. 